\title{
Predicting topical drug clearance from the skin
}

\author{
Maria Alice Maciel Tabosa ${ }^{1}$ (1) Magdalena Hoppel $^{1} \cdot$ Annette L. Bunge $^{2} \cdot$ Richard H. Guy $^{1}$. \\ M. Begoña Delgado-Charro ${ }^{1}$
}

Accepted: 2 October 2020

(c) The Author(s) 2021

\begin{abstract}
For topical drug products that target sites of action in the viable epidermal and/or upper dermal compartment of the skin, the local concentration profiles have proven difficult to quantify because drug clearance from the viable cutaneous tissue is not well characterised. Without such knowledge, of course, it is difficult—if not impossible — to predict a priori whether and over what time frame a topical formulation will permit an effective concentration of drug within the skin 'compartment' to be achieved. Here, we test the hypothesis that valuable information about drug disposition, and specifically its clearance, in this experimentally difficult-to-access compartment (at least, in vivo) can be derived from available systemic pharmacokinetic data for drugs administered via transdermal delivery systems. A multiple regression analysis was undertaken to determine the best-fit empirical correlation relating clearance from the skin to known or easily calculable drug properties. It was possible, in this way, to demonstrate a clear relationship between drug clearance from the skin and key physical chemical properties of the drug (molecular weight, $\log P$ and topological polar surface area). It was further demonstrated that values predicted by the model correlated well with those derived from in vitro skin experiments.
\end{abstract}

Keywords Skin $\cdot$ Dermato-pharmacokinetics $\cdot$ Skin clearance $\cdot$ Transdermal patch $\cdot$ Drug disposition

\section{Introduction}

Skin disease affects millions of people worldwide [1]. The effective delivery of a locally acting, dermatological drug demands knowledge of its 'skin pharmacokinetics' to determine the rate and extent with which it reaches its site of action in the epidermis/dermis. Of necessity, this requires understanding of not only the input rate of the drug into the skin but also its clearance from the 'skin compartment' into the systemic circulation. In this work, the phrase 'clearance from the skin' is used to mean the volume of skin from which a drug is completely removed per unit time.

For topical drug products that target sites of action in the viable epidermis and/or upper dermal compartment of the skin, the local concentration profiles have proven difficult to quantify because both drug input into the viable cutaneous

Maria Alice Maciel Tabosa

m.a.maciel.tabosa@bath.ac.uk; alice.maciel@nudfac.com.br

1 Department of Pharmacy \& Pharmacology, University of Bath, Bath, UK

2 Department of Chemical \& Biological Engineering, Colorado School of Mines, CO, USA tissue and its clearance therefrom are not well characterised [2]. Without such knowledge, of course, it is difficult-if not impossible - to predict a priori whether and over what time frame a topical formulation will permit an effective concentration of drug to be achieved within the skin compartment.

Mathematical and pharmacokinetic modelling has made a substantial contribution to the interpretation of drug movement and disposition in the skin [3, 4]. However, given the multistep nature of the dermal absorption process, the many formulation types and the complex nature of the physiological barrier, all models suffer from one or more limitations. For example, the need to 'guesstimate' several parameters to permit simulations to be performed, or the incorrect relation of 'rate constants' to drug physicochemical parameters, or the inability to obtain a prediction of drug concentration in the viable epidermis, means that many models (for most dermal products) are of little practical use.

There is a need, therefore, to develop simple, yet realistic and mechanistically meaningful, models to estimate the key dermato-pharmacokinetic parameters. Among the approaches currently under investigation are physiologically based pharmacokinetic (PBPK) models, which consist of physiologically realistic compartmental structures into 
which input parameters from different sources (e.g. in silico predictions, in vitro or in vivo experiments) can be combined to predict plasma and/or tissue concentration-time profiles $[5,6]$.

PBPK models take into account physiological properties of the tissue in question, which are not dependent on the drug and can, therefore, be applied to any compound, as well as characteristics intrinsic to the drug. PBPK models employ a 'bottom-up' approach, as opposed to the 'topdown' approach of classical pharmacokinetic models (e.g. one- or two-compartment approaches) [7]. That is, rather than estimating model parameters based on in vivo data (commonly derived from plasma/blood concentration versus time profiles), PBPK model parameters are determined a priori from in vitro experiments, in silico predictions or, if required, in vivo data.

Nonetheless, most PBPK models require a level of parameter calibration and/or optimisation. In general, a drug's concentration in plasma is determined by the systemic volume of distribution at steady-state $\left(V_{\mathrm{SS}}, \mathrm{L}\right)$, defined as the total amount of drug in the body divided by the drug concentration in the plasma [8], and clearance $(\mathrm{Cl}, \mathrm{L} / \mathrm{h})$, which is the volume of fluid (plasma or blood) cleared of drug per unit time. Assuming a simple one-compartment model with 1st-order elimination from the tissue compartment, the ratio of these independent physiological parameters provides the systemic elimination rate constant $k_{\mathrm{e}}$ (Eq. 1):

$k_{\mathrm{e}}=\mathrm{Cl} / V_{\mathrm{SS}}$

$V_{\mathrm{SS}}$ is an apparent volume that describes the extent of drug distribution and binding to the tissues and plasma (Eq. 2):

$V_{\mathrm{SS}}=V_{\text {plasma }}+\sum_{1}^{n} K_{\mathrm{tissue} / \text { plasma }} \times V_{\text {tissue }, i} \times\left(1-E_{\mathrm{i}}\right)$

where $V_{\text {plasma }}$ is the volume of the plasma and $V_{\text {tissue, } i}$ is the volume of the $i$ th tissue; $K_{\text {tissue/plasma }}$ is the tissue-toplasma partition coefficient; $E_{\mathrm{i}}$ is the tissue extraction ratio and, for non-eliminating tissues, as is generally true of the skin [9]; and $E_{\mathrm{i}}$ equals 0 .
In this paper, we test the hypothesis that valuable information about drug disposition, and specifically its clearance from the skin, can be derived from available systemic pharmacokinetic data for drugs administered via transdermal delivery systems. When a transdermal patch is applied, the drug delivery rate to the skin has been determined (the 'input rate') and the resulting systemic plasma concentration versus time profile has been measured both during patch wear and after its removal. The decline in the systemic plasma concentration post-patch removal is characterised by a terminal systemic rate constant $\left(k_{\text {terminal }}\right)$ that typically is much smaller than the elimination rate constant determined following intravenous administration, demonstrating clearly that 'flip-flop' kinetics are operative [10]. In other words, in transdermal drug delivery, the skin desorption rate is normally much slower than the systemic elimination. As a result, the disposition of a drug following transdermal application is usually rate-controlled by skin desorption. We have therefore assumed that the terminal rate constant post-patch removal reflects the elimination rate constant from the skin (i.e. $k_{\mathrm{e}, \mathrm{skin}}=k_{\text {terminal }}$ ). In addition, we hypothesise as illustrated in Fig. 1 that, in flip-flop conditions, $k_{\text {terminal }}$ is related to the drug's clearance from the skin $\left(\mathrm{Cl}_{\text {skin }}\right)$, via the corresponding 'local' volume of distribution $\left(V_{\mathrm{SS} \text {,skin }}\right)$, and therefore, $k_{\mathrm{e}, \mathrm{skin}}$ can be related to key physicochemical parameters of the drug.

To test this hypothesis, the transdermal delivery literature has been searched and values of $k_{\text {terminal }}$ identified for the 18 drugs present in 25 FDA-approved products (FDA Orange Book database of the end of 2017) for this route of administration (see Table 1). Information was also included (Table 1) on a lidocaine patch, for which systemic pharmacokinetic data are available, even though this product is administered to elicit a local rather than systemic pharmacological effect. Importantly, the physicochemical properties of these transdermal drugs are quite broad: for example, molecular weights (MW) between 160 and $470 \mathrm{Da}$ and logarithm of the octanol-water partition coefficient $(\log P)$ values from 1.0 to 5.0 (Table 2 ).
Fig. 1 Schematic of the approach for estimating drug clearance from the skin from post-transdermal patch

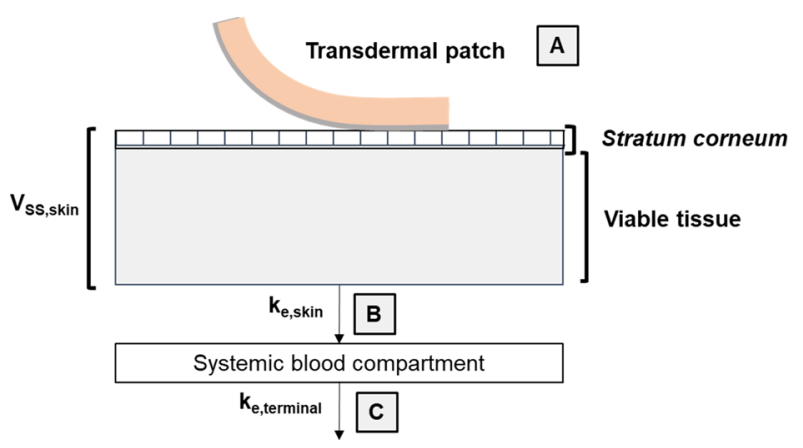

A Removal of the transdermal patch

B $k_{e, s k i n}=\frac{C l_{\text {skin }}}{V_{S S, \text { skin }}}$

C $k_{e, \text { terminal }}=k_{e, \text { skin }}$ 
Table 1 Reported values of $k_{\text {terminal }}, V_{\mathrm{SS}} / \mathrm{BW}, F_{\mathrm{i}, \mathrm{pH}=7.4}, f_{\mathrm{u}, \mathrm{p}}$ and predicted values for $K_{\text {(skin/p) }}$ and $V_{\mathrm{SS}, \mathrm{skin}} / \mathrm{BW}$ of 19 transdermal drugs

\begin{tabular}{|c|c|c|c|c|c|c|c|}
\hline Drug & Trade name & $k_{\mathrm{e}, \text { terminal }}^{\mathrm{a}}\left(\mathrm{h}^{-1}\right)$ & $\begin{array}{l}V_{\mathrm{SS}} / \mathrm{BW}^{\mathrm{b}} \\
\left(\mathrm{L} \mathrm{kg}^{-1}\right)\end{array}$ & $F_{\mathrm{i}, \mathrm{pH}=7.4}^{\mathrm{c}}$ & $f_{\mathrm{u}, \mathrm{p}}^{\mathrm{d}}$ & $K_{\text {(skin/p) }}{ }^{\mathrm{e}}$ & $V_{\mathrm{SS}, \mathrm{skin}} / A_{\text {skin }}{ }^{\mathrm{f}}(\mathrm{cm})$ \\
\hline Buprenorphine & Butrans ${ }^{\circledR}$ & 0.025 & 6.1 & 0.87 & 0.04 & 3.5 & 0.50 \\
\hline Clonidine & Catapress-TTS® & 0.037 & 2.9 & 0.81 & 0.80 & 1.6 & 0.24 \\
\hline Estradiol $^{\mathrm{g}}$ & $\begin{array}{l}\text { Estraderm }{ }^{\circledR} \\
\text { Climara }{ }^{\circledR} \\
\text { Vivelle }{ }^{\circledR} \\
\text { Alora }{ }^{\circledR} \\
\text { Vivelle-dot }{ }^{\circledR} \\
\text { Menostar }{ }^{\circledR} \\
\text { Minivelle }{ }^{\circledR}\end{array}$ & 0.22 & 1.0 & 0 & 0.02 & 2.0 & 0.30 \\
\hline $\begin{array}{c}\text { Estradiol }(\mathrm{E}) \text { and } \\
\text { norethisterone } \\
\text { acetate }^{\mathrm{h}} \text { (NAc) }\end{array}$ & Combipatch ${ }^{\circledR}$ & $\begin{array}{c}\text { E: } 0.22 / N A c: \\
0.046\end{array}$ & E: $1.0 / \mathrm{NAc}: 4.0$ & 0 & $\begin{array}{l}\text { E: } 0.02 / \mathrm{NAc}: \\
0.03\end{array}$ & E: 2.0 / NAc: 4.2 & E: $0.30 / N A c: 0.57$ \\
\hline $\begin{array}{l}\text { Estradiol (E) and } \\
\text { levonorgestrel } \\
\text { (L) }\end{array}$ & Climara Pro® & E: $0.22 / L: 0.021$ & E: 1.0/L: 1.8 & 0 & E: 0.02/L: 0.06 & E: 2.0/L: 2.3 & E: 0.30/L: 0.34 \\
\hline $\begin{array}{l}\text { Ethinyl estradiol } \\
\text { (EE) and } \\
\text { norelgestromin } \\
\text { (N) }\end{array}$ & Xulane ${ }^{\circledR}$ & $\begin{array}{c}\text { EE: } 0.05 / \mathrm{N} \text { : } \\
0.025\end{array}$ & EE: $5.0 / \mathrm{N}: 3.0$ & 0 & EE: $0.05 / \mathrm{N}: 0.03$ & EE: $4.4 / \mathrm{N}: 4.2$ & EE: $0.64 / \mathrm{N}: 0.62$ \\
\hline Fentanyl & Duragesic $®$ & 0.034 & 6.0 & 0.97 & 0.16 & 3.2 & 0.46 \\
\hline $\begin{array}{l}\text { Glyceryl } \\
\text { trinitrate }^{\mathrm{j}}\end{array}$ & $\begin{array}{l}\text { Nitro-Dur® } \\
\text { Minitran }{ }^{\circledR}\end{array}$ & 2.08 & 3.3 & 0 & 0.40 & 2.3 & 0.33 \\
\hline Granisetron & Sancuso® & 0.021 & 3.0 & 1.00 & 0.35 & 1.7 & 0.25 \\
\hline Lidocaine & Lidoderrn ${ }^{\circledR}$ & 0.12 & 1.5 & 0.78 & 0.38 & 1.1 & 0.16 \\
\hline Methylphenidate & Daytrana ${ }^{\circledR}$ & 0.20 & 2.6 & 0.99 & 0.85 & 1.6 & 0.22 \\
\hline Nicotine & $\begin{array}{l}\text { Nicoderm } \mathrm{CQ}{ }^{\circledR} \\
\text { Habitrol }{ }^{\circledR}\end{array}$ & 0.21 & 2.5 & 0.75 & 0.95 & 1.4 & 0.21 \\
\hline Oxybutynin & Oxytron ${ }^{\circledR}$ & 0.061 & 2.8 & 0.86 & 0.09 & 1.9 & 0.28 \\
\hline Rivastigmine & Exelon ${ }^{\circledR}$ & 0.25 & 2.2 & 0.94 & 0.60 & 1.4 & 0.21 \\
\hline Rotigotine & Neupro® & 0.125 & 53.8 & 0.96 & 0.10 & 14.5 & 2.10 \\
\hline Scopolamine & $\begin{array}{c}\text { Transderm } \\
\text { Scop }{ }^{\circledR}\end{array}$ & 0.073 & 1.0 & 0.80 & 0.90 & 0.8 & 0.11 \\
\hline Selegiline & Emsam ${ }^{\circledR}$ & 0.034 & 26.5 & 0.57 & 0.06 & 7.9 & 1.14 \\
\hline Testosterone & Androderm $®$ & 0.37 & 1.0 & 0 & 0.01 & 1.6 & 0.23 \\
\hline
\end{tabular}

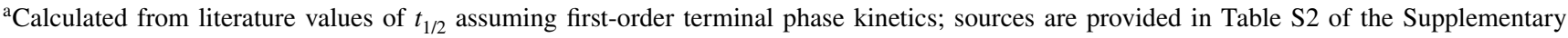
Information

${ }^{\mathrm{b}}$ Deduced from pharmacokinetic data obtained after administration of the drug; sources are provided in Table S1 of the Supplementary Information

${ }^{\mathrm{c}}$ Calculated using Eq. 4 for the $\mathrm{p} K_{\mathrm{a}}$ values listed in Table 2

${ }^{\mathrm{d}}$ Extracted from [11]

${ }^{\text {e}}$ Calculated using correlations described in Table 3

${ }^{\mathrm{f}}$ Calculated using Eq. 3

${ }^{\mathrm{g}}$ Also reported as estradiol

${ }^{\mathrm{h}}$ Also reported as norethindrone acetate

${ }^{\mathrm{i}}$ Also reported as norelgestromin

${ }^{\mathrm{j}}$ Also known as nitroglycerin(e) 
Table 2 Physicochemical properties of the 19 drugs considered

\begin{tabular}{|c|c|c|c|c|c|c|c|c|c|c|c|}
\hline \multirow[t]{2}{*}{ Drug } & \multicolumn{11}{|c|}{ Molecular descriptors } \\
\hline & MW (Da) & $\operatorname{MV}\left(\mathrm{cm}^{3} \mathrm{~mol}^{-1}\right)$ & $\log P$ & $\log D_{7.4}$ & $\mathrm{MP}\left({ }^{\circ} \mathrm{C}\right)$ & TPSA $\left(\AA^{2}\right)$ & HBD & HBA & HBT & RotB & $\mathrm{p} K_{\mathrm{a}}$ \\
\hline Buprenorphine & 467.6 & 368.2 & 4.98 & 3.85 & 219 & 62.2 & 2 & 5 & 7 & 5 & $8.3 / 9.5$ \\
\hline Clonidine & 230.1 & 153.1 & 1.59 & 1.33 & 130 & 36.4 & 2 & 3 & 5 & 1 & 8.0 \\
\hline Estradiol & 272.4 & 232.6 & 4.01 & 3.36 & 179 & 40.5 & 2 & 2 & 4 & 0 & 10.3 \\
\hline Ethinyl estradiol & 296.4 & 244.4 & 3.67 & 3.54 & 163 & 40.5 & 2 & 2 & 4 & 1 & 10.3 \\
\hline Fentanyl & 336.5 & 309.3 & 4.05 & 3.44 & 86 & 23.5 & 0 & 3 & 3 & 6 & 9 \\
\hline Glyceryl trinitrate & 227.1 & 135.8 & 1.62 & 2.00 & 13 & 174.2 & 0 & 12 & 12 & 8 & - \\
\hline Granisetron & 312.4 & 234.8 & 2.12 & 1.04 & 156 & 50.2 & 1 & 5 & 6 & 2 & $10.5 / 12.3$ \\
\hline Levonorgestrel & 312.4 & 274.3 & 3.33 & 3.15 & 228 & 37.3 & 1 & 2 & 3 & 2 & 13.6 \\
\hline Lidocaine & 234.3 & 228.3 & 2.44 & 1.66 & 69 & 32.3 & 1 & 3 & 4 & 5 & 8 \\
\hline Methylphenidate & 233.3 & 218.0 & 2.33 & 0.70 & 225 & 38.3 & 1 & 3 & 4 & 4 & 9.4 \\
\hline Nicotine & 162.2 & 157.1 & 1.17 & 0.13 & -79 & 16.1 & 0 & 2 & 2 & 1 & $3.2 / 8$ \\
\hline Norelgestromin & 327.5 & 265.0 & 4.34 & 4.07 & 226 & 52.8 & 2 & 3 & 5 & 2 & $11.3 / 13.1$ \\
\hline Norethisterone acetate & 340.5 & 296.1 & 3.72 & 3.55 & 171 & 43.4 & 0 & 3 & 3 & 3 & - \\
\hline Oxybutynin & 357.5 & 325.7 & 3.96 & 3.83 & 130 & 49.8 & 1 & 4 & 5 & 10 & $8.2 / 12$ \\
\hline Rivastigmine & 250.3 & 241.1 & 2.24 & 2.30 & 67 & 32.8 & 0 & 4 & 4 & 5 & 8.6 \\
\hline Rotigotine & 315.5 & 272.0 & 4.79 & 3.28 & 136 & 51.7 & 3 & 1 & 4 & 6 & $8.8 / 10.5$ \\
\hline Scopolamine & 303.1 & 230.9 & 0.98 & 0.51 & 59 & 71.5 & 1 & 5 & 6 & 5 & 8 \\
\hline Selegiline & 187.3 & 196.1 & 2.90 & 2.75 & 142 & 3.2 & 0 & 1 & 1 & 5 & 7.5 \\
\hline Testosterone & 288.4 & 256.9 & 3.32 & 3.02 & 138 & 37.3 & 1 & 2 & 3 & 0 & - \\
\hline
\end{tabular}

$M W$ molecular weight, $M V$ molecular volume, $P$ octanol-water partition coefficient, $D_{7.4}$ octanol-pH 7.4 buffer distribution coefficient, $M P$ melting point, TPSA topological polar surface area, $H B A$ number of $\mathrm{H}$-bond acceptors, $H B D$ number of $\mathrm{H}$-bond donors, $H B T \mathrm{HBA}+\mathrm{HBD}$, RotB number of rotatable bonds, $p K_{a}$ negative $\log _{10}$ (acid dissociation constant)

\section{Materials and methods}

Evaluation of dermal drug clearance $\left(\mathrm{Cl}_{\text {skin }}\right)$ involved the following steps: (i) identifying the terminal half-life $\left(t_{1 / 2}\right)$ and the corresponding terminal rate constant $\left(k_{\text {terminal }}\right)$ from the drug's systemic plasma concentration versus time profile after removal of a transdermal patch, (ii) estimating the drug's volume of distribution in the skin $\left(V_{\mathrm{SS} \text {,skin }}\right)$ and, finally, (iii) calculating drug clearance from the skin assuming $k_{\mathrm{e}, \text { skin }}=k_{\text {terminal }}$.

\section{Identifying the terminal half-life $\left(t_{1 / 2}\right)$ and rate constant ( $\left.\boldsymbol{k}_{\text {terminal }}\right)$}

A literature search of pharmacokinetic studies performed on 19 transdermally delivered drugs provided information from which the terminal half-lives $\left(t_{1 / 2}\right)$ were derived. The literature search used PubMed and different combinations of the keywords: 'cutaneous', 'skin', 'transdermal patch', 'pharmacokinetic' and 'clearance'. Pharmacokinetic information was also obtained from relevant Drug@FDA public repositories (https://www.accessdata.fda.gov/scrip ts/cder/daf/, FDA-Clinical Pharmacology and Biopharmaceutics Review(s),). The data used were from healthy adults (18-71 years; $n \geq 5$ ), and the $C_{\mathrm{p}}$ versus time profiles analysed had at least 3 measurements after patch removal. There were, however, two exceptions: (i) as almost all studies involving testosterone were performed on patients with hypogonadism, these data were accepted for analysis; and (ii) similarly, for methylphenidate, the only data available were from children (6-12 years).

When not specifically reported, $t_{1 / 2}$ values were extracted from $C_{\mathrm{p}}$ versus time profiles assuming that the terminal phase kinetics were first-order (i.e. $t_{1 / 2}=\ln (2) / k_{\text {terminal }}$ ). The half-lives were derived from graphs using WebPlotDigitizer software (version 3.10, Ankit Rohatgi; Austin, TX, USA), and $k_{\text {terminal }}$ values were deduced (Table 1 and Table S2) (together with the corresponding references) in the Supplementary Information). If data from more than one source were available, an arithmetic mean of the $k_{\text {terminal }}$ values was calculated.

\section{Estimating the drug's volume of distribution in the skin}

Equation 2 indicates that each tissue/organ contributes to the overall total volume of distribution $\left(V_{\mathrm{SS}}\right)$ of the drug and suggests that $V_{\mathrm{SS} \text {,skin }}$ can therefore be approximated by the following: 
$V_{\mathrm{SS}, \text { skin }} / A_{\text {skin }}=\left(V_{\text {skin }} / A_{\text {skin }}\right) \times K_{(\text {skin } / \mathrm{p})}$

where $V_{\text {skin }}$ and $A_{\text {skin }}$ are respectively the volume and area of the skin compartment, and $K_{\text {(skin/p) }}$ is the drug's partition coefficient between the skin and the plasma. It is relevant to point out that protein binding can occur within the skin (in the stratum corneum (SC) and/or the viable skin) and that $K_{\text {(skin/p) }}$ is likely to be greater than 1, therefore. Also, as most transdermal drugs are either neutral compounds or weak bases, the degree of ionisation of the latter is an important parameter to consider as well.

Correlations listed in Table 3 have been developed by Yun and Edginton [8] to predict $K_{(\mathrm{skin} / \mathrm{p})}$ in the rat from physicochemical descriptors ( $\log P$, degree of ionization $\left(F_{\mathrm{i}}\right)$ and plasma protein binding $\left.\left(f_{\mathrm{u}, \mathrm{p}}\right)\right)$ together with organism-specific information (specifically, the ratio of the systemic volume to body weight $\left(V_{\mathrm{SS}} / \mathrm{BW}, \mathrm{L} \mathrm{kg}^{-1}\right)$ in the rat) for moderate to strong bases ( $\mathrm{p} K_{\mathrm{a}} \geq 7.4$, equation A) and for acids and neutral compounds, zwitterions and weak bases ( $\mathrm{p} K_{\mathrm{a}} \leq 7.4$, equation B) [8].

To adapt this approach to estimate $V_{\mathrm{SS} \text {,skin }}$ in humans using Eq. $3, V_{\text {skin }}$ and $A_{\text {skin }}$ were assumed to be $2.6 \mathrm{~L}$ and $1.8 \mathrm{~m}^{2}$ (based on a standard body weight of $70 \mathrm{~kg}$, [12]) and $K_{(\mathrm{skin} / \mathrm{p})}$ was determined from either equation $\mathrm{A}$ or B (Table 3 ) using the appropriate $V_{\mathrm{SS}} / \mathrm{BW}$. We note that the dermis makes up $95-96 \%$ of the total skin weight in humans and the epidermis makes up the remainder [12]. As Yun and Edginton [8] did not distinguish between the different skin layers, it was assumed here that $K_{(\mathrm{skin} / \mathrm{p})}$ is the average value for all skin layers.

Ideally, in the selection of an appropriate model for determination of $K_{(\mathrm{skin} / \mathrm{p})}$, a determination must be made as to how accurately the selected model reflects the properties of the skin and the plasma. One needs to bear in mind that the correlations developed by Yun and Edginton [8] were built using $V_{\mathrm{SS}} / \mathrm{BW}$ from rats. In contrast, in this work, $K_{\text {(skin/p) }}$ predictions were made using $V_{\mathrm{SS}} / \mathrm{BW}$ from humans. This approach was taken due to the absence, at least to the authors' knowledge, of a model/correlation for $K_{\text {(skin/p) }}$ prediction using human data. Although rat skin is commonly used in in vitro and in vivo percutaneous studies [13, 14], its properties do not perfectly mimic human skin [14-17]. However, in comparison with human skin, rat skin does have a similar stratum corneum (SC) thickness, although a slightly thinner epidermis and total skin thickness [14].
Values of the steady-state systemic drug volume of distribution per $\mathrm{BW}$ in humans $\left(V_{\mathrm{SS}} / \mathrm{BW}\right)$ and the plasma protein binding $\left(f_{\mathrm{u}, \mathrm{p}}\right)$ were obtained from the literature (Table 1). The relevant drug physicochemical properties are listed in Table 2. The degree of ionization $\left(F_{\mathrm{i}}\right)$ at physiological $\mathrm{pH}$ $7.4\left(F_{\mathrm{i}, \mathrm{pH}=7.4}\right)$ for a chemical was calculated in the normal way using Eq. 4:

$F_{\mathrm{i}, \mathrm{pH}=7.4}=1-\left(\frac{1}{1+10^{g\left(7.4-\mathrm{pK} K_{\mathrm{a}}\right)}}\right)$

where $g=+1$ for a monoprotic acid and -1 for monoprotic base. Table 1 lists $V_{\mathrm{SS}, \text { skin }} / A_{\text {skin }}$ as well as the parameter values used in its calculation (i.e. $V_{\mathrm{SS}} / \mathrm{BW}, f_{\mathrm{u}, \mathrm{p}}, F_{\mathrm{i}, \mathrm{pH}}=7.4$ and $\left.K_{(\text {skin/p) }}\right)$.

\section{Calculating drug clearance from the skin}

Finally, assuming that skin pharmacokinetics can be described using a one-compartmental model with first-order elimination kinetics, $\mathrm{Cl}_{\text {skin }} / A_{\text {skin }}$ (which has units of $\mathrm{cm} \mathrm{h}^{-1}$, i.e. the same as those for the skin permeability coefficient) was calculated using Eq. 5.

$\mathrm{Cl}_{\text {skin }} / A_{\text {skin }}=k_{\text {e,skin }} \times V_{\text {SS,skin }} / A_{\text {skin }}$

\section{Drug physicochemical parameters}

The molecular descriptors are as follows: $\log P$, molecular weight (MW) and melting point (MP) are from EPA's CompTox Chemistry Dashboard (https://comptox.epa.gov/ dashboard), which includes experimental values that were used when available. When several experimental values were available, the mean value was used. In addition, the logarithm of the octanol-water distribution coefficient at $\mathrm{pH}=7.4\left(\log \mathrm{D}_{7.4}\right)$, the number of rotatable bonds (RotB), the numbers of hydrogen-bond acceptors (HBA) and donors (HBD) and their sum (HBT), molecular volume (MV), topological polar surface area (TPSA) and $\mathrm{p} K_{\mathrm{a}}$ were calculated using ACD/Labs (Toronto, Canada, version 5.0). The physicochemical properties of the 19 drugs are listed in Table 2.

\section{Multiple linear regression model development}

Multiple linear regression (MLR), using the ordinary least squares (OLS) method, was used to develop an empirical
Table 3 Correlations for predicting drug skin-to-plasma partition coefficients $\left(K_{(\mathrm{skin} / \mathrm{p})}\right)$ in rats. Table adapted from Yun and Edginton [8]

\begin{tabular}{llll}
\hline Equation & Regression equation & Number & $R^{2}$ \\
\hline A & $\log K_{(\text {skin } / \mathrm{p})}=-0.144+0.663\left(\log V_{\mathrm{SS}} / \mathrm{BW}\right)+0.033(\log P)$ & 28 & 0.80 \\
$\mathrm{~B}$ & $\log K_{(\text {skin } / \mathrm{p})}=-0.331+0.544\left(\log V_{\mathrm{SS}} / \mathrm{BW}\right)+0.158(\log$ & 26 & 0.73 \\
& $P)-0.318\left(F_{\mathrm{i}}\right)+0.384\left(f_{\mathrm{u}, \mathrm{p}}\right)$ & & \\
\hline
\end{tabular}


relationship that best described the dependence of the log transformed area normalised skin clearance $\left(\log \mathrm{Cl}_{\text {skin }} / A_{\text {skin }}\right)$ on the key physicochemical properties of the drug. Stepwise MLR was performed using The Unscrambler® X software (Version 10.5, Camo A/S, Oslo, Norway). In each regression analysis, a variable was either added or removed until the fit obtained had the highest adjusted and predicted coefficient of determination $\left(R^{2}\right)$ and when all the predictors were statistically significant ( $p$ value $\leq 0.05$ ). In addition, collinearity between predictor values was assessed by screening the variance inflation factor (VIF) for each equation; a VIF $=5$ was the cut-off criterion [18].

Subsequently, internal validations were undertaken to estimate the predictive value of the final model, defined by the determination coefficients of leave-25\%-out $\left(Q^{2}{ }_{25 \%}\right)$ and of leave-one-out cross-validation $\left(Q_{\text {LOO }}^{2}\right)$ [19]. In leave$25 \%$-out cross-validation, the data set for the 19 compounds were randomly divided into training $(n=14)$ and test $(n=5)$ groups. Then, coefficients of determination $\left(R^{2}\right)$ and prediction $\left(Q^{2}{ }_{25 \%}\right)$ were obtained by regressing the parameters of the model equation to random combinations of the 14 training observations. The calculation of $Q_{\text {LOO }}^{2}$ involved the omission of the data for one drug and re-determining the regression model using the remaining 18 data. The resulting equation is then used to predict the dermal clearance of the omitted chemical. The correlation between the predicted and observed values in the newly generated dermal clearance data set is used to judge the fit. $Q^{2}{ }_{\text {LOO }}$ is therefore able to validate the model without additional compounds or splitting the data.

\section{Model verification using in vitro skin permeation}

In vitro permeation experiments were performed to measure the rate at which three drugs (buprenorphine (BUP), nicotine (NIC) and diclofenac (DF)) are cleared from the skin following application of examples of commercially available transdermal patches. The transdermal patches tested were the following: Transtec ${ }^{\circledR}\left(35 \mu \mathrm{g} \mathrm{h}^{-1}, 20 \mathrm{mg}\right.$ of buprenorphine over $25 \mathrm{~cm}^{2}$ ) from NAPP (Cambridge, UK), Nicotinell ${ }^{\circledR}$ ( $7 \mathrm{mg} / 24 \mathrm{~h}, 17.5 \mathrm{mg}$ of nicotine over $10 \mathrm{~cm}^{2}$ ) from Novartis (Camberley, UK) and Voltaren ${ }^{\circledR}$ (medicated plaster, $180 \mathrm{mg}$ of diclofenac epolamine over $140 \mathrm{~cm}^{2}$ ) was from GlaxoSmithKline (Munich, Germany). Experiments were carried out in static, Franz diffusion cells (Permegear, Hellertown, PA, USA) with a receptor volume of $\sim 7.4 \mathrm{~mL}$. Porcine skin (thickness $\sim 750 \mu \mathrm{m}$ ) from a single pig, sourced, stored and prepared as previously described [20] was used. A 1.54$\mathrm{cm}^{2}$ disk of the patch was applied to the skin surface before mounting in the Franz cell; 10 passes of a custom-made, weighted roller ensured complete adhesion between patch and skin. After assembly of the diffusion cell, the lower compartment was filled with a drug-specific receptor solution (Table 4). The patch was applied for a specific 'uptake time' and then removed; subsequently, the skin remained mounted in the diffusion cell for a further 'clearance time' (or times) (Table 4), at the end of which the experiment was terminated. Six replicates of all measurements were made. 'Uptake times' were chosen to be sufficiently long that steady-state diffusion had been achieved; 'clearance times' were selected such that an obviously significant reduction in the quantity of drug taken up into the skin had occurred without compromising the ability to detect that remaining.

After dismantling the diffusion cell, the SC was removed by repeated tape-stripping. Templates (Scotch ${ }^{\circledR}$ Book Tape, 3M, St. Paul, MN, USA), with a circular internal area that matched the $1.54-\mathrm{cm}^{2}$ patch area, were positioned on the skin, and then a total of 20 adhesive tape strips $\left(2.0 \mathrm{~cm} \times 2.5 \mathrm{~cm}\right.$, Scotch ${ }^{\circledR}$ Book Tape) were sequentially applied, pressed down firmly and quickly removed. Drug was extracted from the individual tapes (Table 4) and the total amount therein was quantified by HPLC (Dionex, UK) (Table 5). The quantity of drug in the remaining skin tissue was also determined with the same analytical procedure after extraction. The concentrations of the three drugs in the receptor solution (measured at the end of each experiment by HPLC) were always less than one-tenth of the corresponding aqueous solubilities confirming that sink conditions
Table 4 In vitro skin permeation experimental details

\begin{tabular}{llll}
\hline & Buprenorphine & Nicotine & Diclofenac \\
\hline Receptor solution & $20: 80$ PEG 400-PBS & PBS 10 mM & PBS 10 mM \\
& $10 \mathrm{mM}+0.01 \%$ sodium azide & & \\
'Uptake' time (h) & 72 & 2 & 6 \\
'Clearance' time(s) (h) & 24 & $1.5,3.0$ & $5,17,24$ \\
Extraction solution $^{\mathrm{a}}$ & $40: 60$ ACN:TFA & $40: 60$ ACN-PBS 10 & $\mathrm{MeOH}^{\mathrm{a}}$ \\
& & $\mathrm{mM}^{\mathrm{b}}$ & \\
\hline
\end{tabular}

PEG polyethylene glycol, $P B S$ phosphate-buffered saline (pH 7.4), ACN acetonitrile, TFA trifluoroacetic acid $0.03 \% \mathrm{v} / \mathrm{v}, \mathrm{MeOH}$ methanol

${ }^{a}$ Extraction volumes were $1.5 \mathrm{~mL}$ for tape strips and either $4 \mathrm{~mL}$ (buprenorphine, diclofenac) or $8 \mathrm{~mL}$ (nicotine) for remaining skin. Mean extraction efficiencies from tape strips and from the remaining skin were $>89 \%$. 
Table 5 HPLC-UV

method conditions used for quantification of BUP, NIC and DF

\begin{tabular}{llll}
\hline HPLC parameters & Buprenorphine & Nicotine & Diclofenac \\
\hline Mobile phase $^{\mathrm{a}}$ & $22: 19: 59$ & $35: 35: 30$ & $75: 25$ \\
& ACN:MeOH:TFA & ACN:MeOH:PBS & MeOH:formic acid \\
Oven temperature $\left({ }^{\circ} \mathrm{C}\right)$ & 25 & 25 & 40 \\
Flow rate $\left(\mathrm{mL} \mathrm{min}{ }^{-1}\right)$ & 1.0 & 1.0 & 1.2 \\
Retention time $(\mathrm{min})$ & 11.8 & 3.2 & 7.3 \\
Injection volume $(\mu \mathrm{L})$ & 75 & 50 & 100 \\
UV detection $(\mathrm{nm})$ & 220 & 260 & 280 \\
Limit of quantification $\left(\mu \mathrm{g} \mathrm{mL}{ }^{-1}\right)$ & 0.14 & 0.12 & 0.10 \\
\hline
\end{tabular}

${ }^{\text {a }}$ All abbreviations as defined in Table 4

${ }^{\mathrm{b}} 0.1 \% v / v$ in water were maintained. HPLC assays with UV detection, running Chromeleon software, were developed for the three drugs. A HiQSil C18HS analytical reverse phase column $(150 \times 4.6 \mathrm{~mm}$ i.d.; $5 \mu \mathrm{m}$ particle size) (Kromatek, UK) was used. The chromatographic conditions are provided in Table 5 .

\section{Results and discussion}

The analysis of the literature for 19 different drugs identified more than 70 specific studies that yielded a total of 160 terminal half-life values. In some cases (such as scopolamine and norethisterone acetate), only a single half-life was found while, for other drugs (such as nicotine and ethinyl estradiol), 20 individual half-life values were discovered. The distribution of the half-lives for each drug is presented as a box-and-whisker plot in Fig. 2. From the half-life value, $k_{\text {terminal }}\left(=(\ln 2) / t_{1 / 2}\right)$ for each drug was then calculated (see 'Supplementary Information', Table S2 together with the corresponding references).

To estimate the area-normalised volumes of distribution in the skin $\left(V_{\mathrm{SS}, \mathrm{skin}} / A_{\text {skin }}\right)$ of the 19 drugs, the skin-to-plasma partition coefficients $\left(K_{(\mathrm{skin} / \mathrm{p})}\right)$ were first determined using the equations in Table 3; values ranged from 0.8 for scopolamine to 14.5 for rotigotine (Table 1 ). The relatively high $K_{\text {(skin/p) }}$ of the latter drug was not unexpected as its high lipophilicity $(\log P=4.7)$ and substantial systemic volume of distribution $\left(V_{\mathrm{SS}} / \mathrm{BW}=53.8 \mathrm{~L} \mathrm{~kg}^{-1}\right)$ already suggest that rotigotine is likely to accumulate in tissues. Likewise, scopolamine's smaller lipophilicity $(\log P \sim 1)$ and relatively small volume of distribution $\left(V_{\mathrm{SS}} / \mathrm{BW}=1.0 \mathrm{~L} \mathrm{~kg}^{-1}\right)$ are completely consistent with its much smaller $K_{(\text {skin/p) }}$. It is worth mentioning that there is only an 18 -fold difference in skin partitioning between rotigotine and scopolamine despite the more than 4000-fold difference in their octanol-water partition coefficients. This is consistent with a skin compartment that is dominated by the 'viable' skin layers rather than the SC. The skin-plasma partitioning represents, therefore, the equilibrium between the relatively hydrophilic layers of the skin and hydrophilic plasma.

From the calculated $K_{\text {(skin/p) }}$ for each drug and the $V_{\text {skin }} / A_{\text {skin }}, V_{\mathrm{SS} \text {,skin }} / A_{\text {skin }}$ was then calculated from Eq. 3; the results are listed in Table 1. Finally, drug clearance from the skin $\left(\mathrm{Cl}_{\text {skin }} / A_{\text {skin }}\right.$ in $\left.\mathrm{cm} \mathrm{h}^{-1}\right)$ was assessed using Eq. 5 and the resulting values are in Table 6.

An empirical model was then derived, using multiple linear regression (MLR), to predict dermal drug clearance. MLR is a statistical technique that can use a number of molecular descriptors to identify predictive, albeit empirical, relationships in data sets. The advantage of MLR is its simplicity and the easily interpretable mathematical results. The sign of the coefficient derived for each molecular descriptor indicates whether it contributes positively or negatively to the predicted parameter and its magnitude is a measure of the relative importance. However, MLR works best when (i) the structure-activity relationship is linear, (ii) the set of molecular descriptors is independent (i.e. descriptors do not show collinearity) and (iii) the number of compounds in the training set exceeds the number of molecular descriptors by at least a factor of five [22].

At the outset, MLR was performed using ten molecular descriptors (MW, $\log P, \mathrm{MP}, \log \mathrm{D}_{7.4}$, RotB, HBA, HBD, HBT, MV and TPSA) as potential predictors of drug clearance from skin; these values for the 19 drugs are listed in Table 2. In the end, a model based only on MW, $\log P$ and TPSA (in units of $\AA^{2}$ ) best explained the calculated dermal clearance (Eq. 6; Table 7; Fig. 3):

$$
\begin{aligned}
\log \left[\mathrm{Cl}_{\text {skin }} / \text { Area }\left(\mathrm{cm} \mathrm{h}^{-1}\right)\right]= & -0.937-0.008(\mathrm{MW}) \\
& +0.391(\log P)+0.011(\mathrm{TPSA})
\end{aligned}
$$

with an adjusted $R^{2}=0.67, Q_{\text {LOO }}^{2}=0.61$ and $p<0.05$ for all three variables; adjusted $R^{2}$ is the square of the determination coefficient adjusted for degrees of freedom; $Q_{\text {LOO }}^{2}$ is the cross-validated (leave-one-out) square of the 
Fig. 2 Box-and-whisker plot of the systemic terminal half-life $\left(t_{1 / 2}\right)$ values reported in the literature for 19 drugs following transdermal patch removal. The boxes comprise the median (line), mean (dot) and 25th and 75 th percentile (ends) values. The bars reflect the minimum and maximum values observed. The number $(n)$ of half-lives found for each drug are listed on the right of the graph

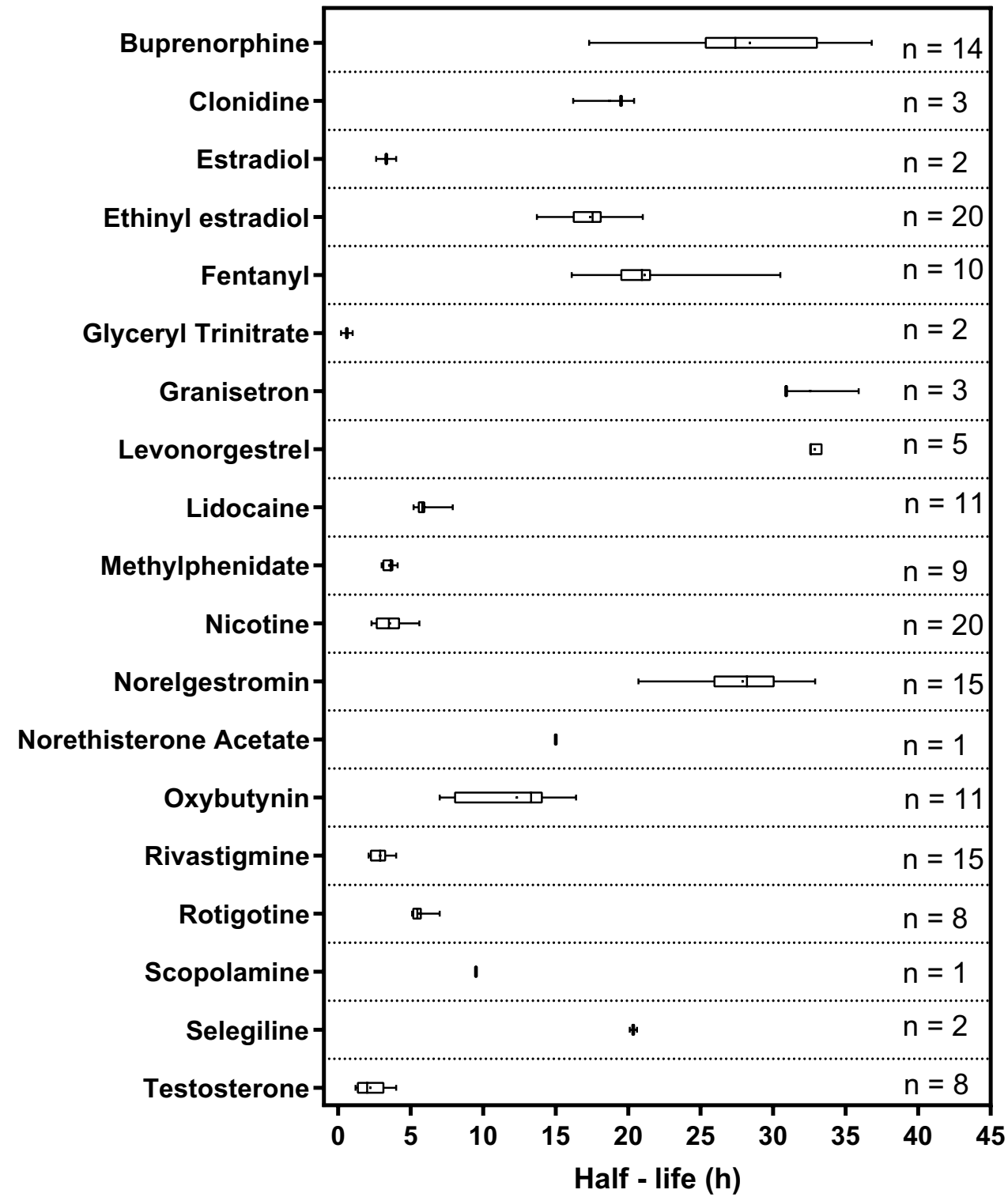

determination coefficient; and the $p$ value is related to the significance of the parameters (Table 7).

The general principle of cross-validation is to split data into training and test sets. The former is used to fit the model while the latter serves to evaluate the fitted model's predictive adequacy. Leave-one-out (LOO) cross-validation repeatedly partitions the data set into a training set which consists of all data points except one and then evaluates the predictive density for the held-out data point where predictions are generated based on the leave-one-out posterior distribution. The LOO estimator is nearly unbiased. Moreover, there was no evidence of collinearity in the predictors, with all VIF values being less than 5 .

On the other hand, due to the small size of the data set here, the leave-25\%-out cross-validation, which is normally employed when the data set is large, is highly variable and depends on which observations are in the training and test sets. To illustrate this point, the leave-25\%-out cross-validation was performed 10 times and yielded the results in Table 8. Clearly, regressions using the same data set (but different subsets) produced quite different results (e.g. compare regressions II and X). Therefore, for the relatively small data set involved in this study, the LOO is a preferable and more appropriate method of validation.

In general, drug permeability across biomembranes, including the skin, increases with increasing permeant lipophilicity and decreases with increasing molecular size [23-26]. It is, therefore perhaps, not surprising that both log $P$ and MW appear in the empirical relation describing drug clearance from the skin. TPSA was also found to be a significant predictor of drug clearance from the skin. TPSA is a molecular property related to the polarity, hydrogen-bonding 
Table $6 \mathrm{Cl}_{\text {skin }} / A_{\text {skin }}$ (expressed as a logarithm) determined via Eq. 5 from the experimental data and the corresponding values predicted from multiple linear regression (Eq. 6)

\begin{tabular}{llll}
\hline ID & Drug & \multicolumn{2}{l}{$\log \left[\mathrm{Cl}_{\text {skin }} / A_{\text {skin }}\left(\mathrm{cm} \mathrm{h}^{-1}\right)\right]$} \\
\cline { 3 - 4 } & & Experimental & Predicted \\
\hline 1 & Buprenorphine & -1.90 & -2.03 \\
2 & Clonidine & -2.05 & -1.74 \\
3 & Estradiol & -1.18 & -1.09 \\
4 & Ethinyl estradiol & -1.59 & -1.41 \\
5 & Fentanyl & -1.81 & -1.78 \\
6 & Glyceryl trinitrate & -0.16 & -0.14 \\
7 & Granisetron & -2.28 & -2.03 \\
8 & Levonorgestrel & -2.15 & -1.71 \\
9 & Lidocaine & -1.72 & -1.49 \\
10 & Methylphenidate & -1.36 & -1.45 \\
11 & Nicotine & -1.35 & -1.59 \\
12 & Norelgestromin & -1.81 & -1.26 \\
13 & Norethisterone acetate & -1.58 & -1.71 \\
14 & Oxybutynin & -1.77 & -1.69 \\
15 & Rivastigmine & -1.28 & -1.69 \\
16 & Rotigotine & -0.58 & -1.00 \\
17 & Scopolamine & -2.10 & -2.16 \\
18 & Selegiline & -1.41 & -1.28 \\
19 & Testosterone & -1.07 & -1.52 \\
\hline
\end{tabular}

potential and water solubility of organic molecules [27, 28]. TPSA has been shown to be inversely correlated with drug transport across the brain-blood barrier $[29,30]$ and the intestinal membrane [31-33], and the positive correlation found here is therefore somewhat surprising. While an increase in hydrogen bonding activity (both acceptor and donor) has been shown to result in a decrease in the partitioning into the organic phase due to the free energy cost associated with the disruption of the hydrogen bonds in the aqueous phase [34], the positive correlation observed with skin clearance may indicate the eventual importance of aqueous solubility in the sequential processes involved in drug elimination from the skin $[35,36]$. Further speculation on this issue, in the absence of additional data, however, is not warranted at this time.

Table 7 Statistics of the descriptors of the MLR model (Eq. 6) developed to predict $\log \left(\mathrm{Cl}_{\text {skin }} / A_{\text {skin }}\right)$

\begin{tabular}{llll}
\hline Descriptor & $\begin{array}{l}\text { Variance inflation } \\
\text { value (VIF) }\end{array}$ & $\begin{array}{l}\text { Derived coeffi- } \\
\text { cients } \pm \text { standard error }\end{array}$ & $p$ value \\
\hline Intercept & - & $-0.921 \pm 0.318$ & 0.0110 \\
MW & 2.2 & $-0.008 \pm 0.002$ & 0.0001 \\
$\log P$ & 2.2 & $0.389 \pm 0.090$ & 0.0006 \\
TPSA & 1.2 & $0.011 \pm 0.002$ & 0.0002 \\
\hline
\end{tabular}

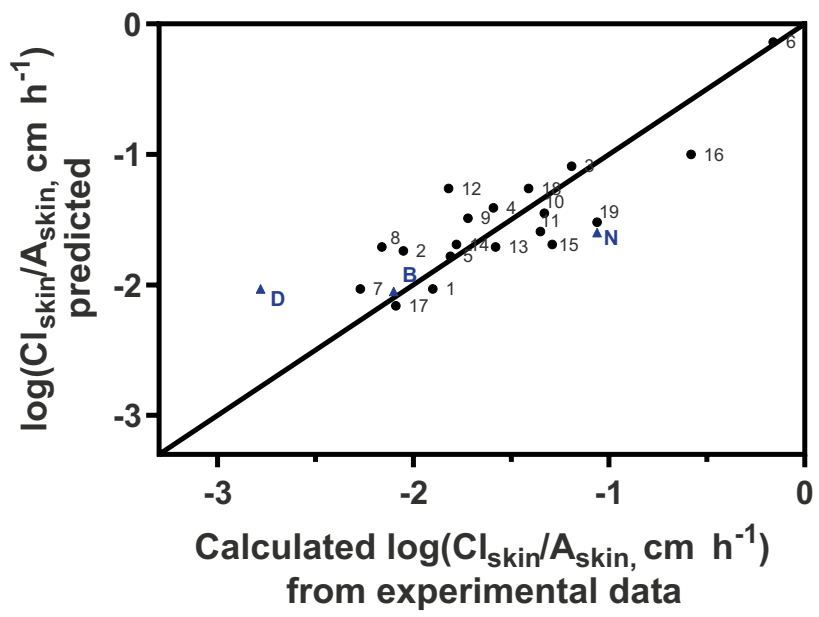

Fig. 3 Relationship between $\log \mathrm{Cl}_{\text {skin }} / A_{\text {skin }}$ calculated from experimental data and that predicted by the MLR-derived Eq. 6. The solid line is the line of identity. The number against each point corresponds to that assigned to each of the 19 drugs in Table 6 . The blue triangles show the predicted $\log \mathrm{Cl}_{\text {skin }} / A_{\text {skin }}$ values compared with those calculated from in vitro experiments (see Table 9 below) for buprenorphine (B), nicotine (N) and diclofenac (D)

In an attempt to further validate the predictions of the model, a series of in vitro experiments were performed with three transdermal drug products. The amounts (A, normalised by patch area) of NIC, BUP and DF in the SC (removed by tape stripping), and in the remaining skin, were measured (a) immediately after patch removal (uptake) and, separately, (b) after further periods of time subsequent to patch removal (clearance) and used to calculate the elimination rate constant of the drugs from the skin $\left(k_{\mathrm{e}, \mathrm{skin}}\right)$. Assuming first-order kinetics, $k_{\mathrm{e}, \text { skin }}$ was estimated from the slope of the log-transformed mass (in the SC plus in the epidermis/dermis) versus time data

Table 8 Coefficients of determination $\left(R^{2}\right)$ and determination coefficient of leave-25\%-out $\left(Q^{2} 25 \%\right)$ for 10 regressions on the same data set

\begin{tabular}{llll}
\hline $\begin{array}{l}\text { Regression } \\
\text { number }\end{array}$ & $\begin{array}{l}\text { Drugs omitted (see Table 6 } \\
\text { for code) }\end{array}$ & $R^{2}$ & $Q^{2}{ }_{25 \%}$ \\
\hline I & $1,3,9,15,19$ & 0.81 & 0.25 \\
II & $7,14,15,16,18$ & 0.73 & 0.81 \\
III & $8,9,10,13,19$ & 0.79 & 0.09 \\
IV & $3,5,10,13,15$ & 0.75 & 0.81 \\
V & $1,7,8,9,14$ & 0.71 & 0.50 \\
VI & $5,6,13,15,16$ & 0.50 & 0.81 \\
VII & $1,12,14,17,19$ & 0.81 & 0.50 \\
VIII & $2,8,11,14,17$ & 0.72 & 0.50 \\
IX & $3,5,7,12,19$ & 0.79 & 0.25 \\
X & $6,7,9,16,18$ & 0.40 & 0.36 \\
\hline
\end{tabular}



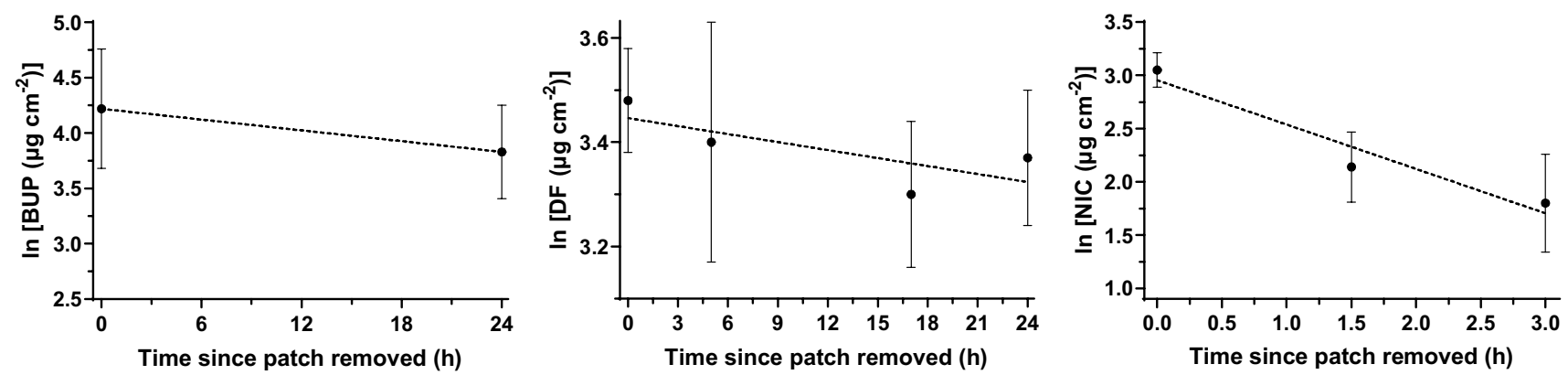

Fig. 4 Amount of drug in the SC + epidermis/dermis (mean \pm standard deviation; $n=6$ ) as a function of the time of clearance. The slopes of the linear regressions (dashed lines) provide the drug elimination rate constants from the skin $\left(k_{\mathrm{e}, \mathrm{skin}}\right)$

Table 9 Measured and deduced dermato-pharmacokinetic parameters for three transdermal drugs, including the skin clearances assessed experimentally in pig skin and empirically predicted (Eq. 6)

\begin{tabular}{|c|c|c|c|c|}
\hline \multicolumn{2}{|l|}{ Drug } & \multirow[t]{2}{*}{ Buprenorphine } & \multirow[t]{2}{*}{ Diclofenac $^{\mathrm{a}}$} & \multirow[t]{2}{*}{ Nicotine } \\
\hline Drug amount $\left(\mu \mathrm{g} \mathrm{cm}^{-2}\right)^{\mathrm{b}}$ & & & & \\
\hline \multirow[t]{3}{*}{ Uptake (BUP 72 h, DF 6 h, NIC 2 h) } & $\mathrm{SC}$ & $29.2 \pm 13.9$ & $25.8 \pm 3.1$ & $7.2 \pm 2.8$ \\
\hline & Remaining skin & $47.7 \pm 25.9$ & $6.8 \pm 1.0$ & $14.2 \pm 5.7$ \\
\hline & Total skin & $76.8 \pm 39.4$ & $32.6 \pm 3.0$ & $21.3 \pm 3.7$ \\
\hline \multirow[t]{3}{*}{ Clearance 1 (BUP 24 h, DF 5 h, NIC 1.5 h) } & $\mathrm{SC}$ & $25.0 \pm 8.4$ & $22.8 \pm 4.8$ & $2.8 \pm 1.6$ \\
\hline & Remaining skin & $24.3 \pm 12.7$ & $7.8 \pm 2.6$ & $6.2 \pm 3.0$ \\
\hline & Total skin & $49.3 \pm 20.2$ & $30.5 \pm 7.0$ & $8.9 \pm 3.0$ \\
\hline \multirow[t]{3}{*}{ Clearance 2 (DF 17 h, NIC 3 h) } & $\mathrm{SC}$ & & $25.2 \pm 3.9$ & $1.6 \pm 0.7$ \\
\hline & Remaining skin & & $2.1 \pm 1.1$ & $5.0 \pm 2.3$ \\
\hline & Total skin & & $27.3 \pm 3.6$ & $6.6 \pm 3.0$ \\
\hline \multirow[t]{3}{*}{ Clearance 3 (DF 24 h) } & $\mathrm{SC}$ & & $27.3 \pm 3.5$ & \\
\hline & Remaining skin & & $2.1 \pm 1.2$ & \\
\hline & Total skin & & $29.4 \pm 3.5$ & \\
\hline$k_{\mathrm{e}, \mathrm{skin}}\left(\mathrm{h}^{-1}\right)^{\mathrm{c}}$ & & 0.016 & 0.005 & 0.42 \\
\hline$V_{\mathrm{SS}} / \mathrm{BW}\left(\mathrm{L} \mathrm{kg}^{-1}\right)$ & & $6.1^{\mathrm{d}}$ & $0.9^{\mathrm{e}}$ & $2.5^{\mathrm{d}}$ \\
\hline$K_{(\mathrm{skin} / \mathrm{p})}$ & & 3.5 & 2.3 & 1.4 \\
\hline$V_{\mathrm{SS}, \text { skin }} / A_{\text {skin }}(\mathrm{cm})^{\mathrm{f}}$ & & 0.50 & 0.33 & 0.21 \\
\hline \multirow[t]{3}{*}{$\mathrm{Cl}_{\text {skin }} / A_{\text {skin }}\left(\mathrm{cm} \mathrm{h}^{-1}\right)$} & In vitro experiment $\mathrm{t}^{\mathrm{g}}$ & 0.0080 & 0.0017 & 0.0874 \\
\hline & In vivo experiment ${ }^{\mathrm{h}}$ & 0.0126 & NA & 0.0447 \\
\hline & predicted $^{\mathrm{i}}$ & 0.0093 & 0.0086 & 0.0251 \\
\hline
\end{tabular}

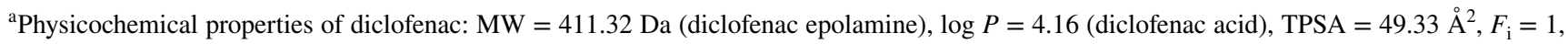
$f_{\mathrm{u}, \mathrm{p}}=0.99, \mathrm{p} K_{\mathrm{a}}=4$

${ }^{\mathrm{b}}$ Drug amounts (A, mean \pm standard deviation, $n=6$ ) recovered after uptake or clearance from the SC, epidermis/dermis, or the sum of both as indicated

${ }^{\mathrm{c}} k_{\mathrm{e}, \text { skin }}$ is the first-order elimination rate constant describing drug clearance from the 'skin compartment' in the in vitro experiments (see Fig. 4)

${ }^{\mathrm{d}}$ Values derived from in vivo studies after IV administration of the drug (the values were collected from drug approval packages for the product name listed on the FDA website; see Table S1 in the Supplementary information)

${ }^{\mathrm{e}}$ Value derived from in vivo studies after oral administration of diclofenac epolamine [37]

${ }^{\mathrm{f}}$ Calculated using Eq. 3

${ }^{\mathrm{g}}$ Calculated using $V_{\mathrm{SS} \text {,skin }} / A_{\text {skin }}$ (from Eq. 3) and the experimentally (in vitro) determined $k_{\mathrm{e}, \text { skin }}$

${ }^{\text {h}}$ Calculated using $V_{\mathrm{SS}, \mathrm{skin}} / A_{\text {skin }}$ (from Eq. 3) and the reported in vivo $k_{\mathrm{e} \text {,terminal }}$ (Table 6)

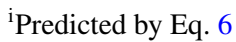


of each drug (Fig. 4). The human systemic steady-state volumes of distribution $\left(V_{\mathrm{SS}} / \mathrm{BW}\right)$ of the drugs were from the literature, and the human skin-to-plasma partition coefficients $\left(K_{(\mathrm{skin} / \mathrm{p})}\right)$ were estimated using equation $\mathrm{A}$ in Table 3. The dermal steady-state volumes of distribution $\left(V_{\text {SS,skin }} / A_{\text {skin }}\right)$ were then calculated using Eq. 3, and the experimental dermal clearances were estimated from Eq. 6. Table 9 summarises the results and compares these in vitro experimental values to the in vivo experimental and predicted values.

Although the experimental skin clearances were derived from in vitro studies using skin from pigs and without a functioning dermal microcirculation, the agreement between these values and those predicted by the empirical model is within a factor of 1.2 for BUP, 5 for DF and 0.29 for NIC. Given the inherent variability in the clinical and laboratory data used to derive the predicted and experimental skin clearances, the degree of overlap between measured and estimated parameters is reasonable. It is worth noting that the 'experimental' clearance values depend on two components: firstly, $k_{\text {e,skin }}$, which is derived either from previously published in vivo experiments in human volunteers wearing transdermal patches, or from the in vitro experiments reported in this study; and, secondly, $V_{\mathrm{SS}, \text { skin }} / A_{\text {skin }}$, which is calculated based on extrapolation of a correlation derived from experiments performed in rats. At present, whether the calculated $V_{\mathrm{SS}, \text { skin }} / A_{\text {skin }}$ values are accurate representations of actual values in man is unknown and it is therefore impossible to say, with any confidence, how well the calculated (or predicted) values of $\mathrm{Cl}_{\text {skin }} / A_{\text {skin }}$ represent human skin. What can be said and, we submit, is a key outcome of this work, is that a scheme for calculation of $\mathrm{Cl}_{\text {skin }} / A_{\text {skin }}$ is now available, the robustness of which will be testable once skin-plasma drug distribution data are available for man. Finally, it should also be mentioned that this work has also demonstrated consistency between results acquired in vitro using pig skin data and in vivo in human subjects.

\section{Conclusions}

The development of an empirical model describing drug clearance from the skin, in terms of the readily available (measured or predicted) parameters, MW, $\log P$ and TPSA, has been presented. The mechanistic significance of these metrics is consistent with the anticipated role of molecular size, hydrophobicity and polarity in the determination of passive drug diffusion in the skin and the compound's eventual uptake into the systemic circulation. An attempt to validate the model's predictive ability against (in vitro) experimentally derived skin clearance values of three drugs resulted in reasonable agreement.
Supplementary Information The online version contains supplementary material available at https://doi.org/10.1007/s13346-020-00864-8.

Author contributions All co-authors contributed to the design and execution of the research and to the writing of the manuscript. Approval of the final version of the manuscript has been given by each of the co-authors.

Funding This research was funded by the CAPES foundation (via the Brazilian 'Science without Borders' programme, grant number 1361413-4), by the Austrian Science Fund (FWF, Erwin-Schrödinger fellowship number J3754-B30) and by The Leo Foundation (grant number LF16117).

\section{Compliance with ethical standards}

Conflict of interest The authors declare that they have no conflict of interest.

Open Access This article is licensed under a Creative Commons Attribution 4.0 International License, which permits use, sharing, adaptation, distribution and reproduction in any medium or format, as long as you give appropriate credit to the original author(s) and the source, provide a link to the Creative Commons licence, and indicate if changes were made. The images or other third party material in this article are included in the article's Creative Commons licence, unless indicated otherwise in a credit line to the material. If material is not included in the article's Creative Commons licence and your intended use is not permitted by statutory regulation or exceeds the permitted use, you will need to obtain permission directly from the copyright holder. To view a copy of this licence, visit http://creativecommons.org/licenses/by/4.0/.

\section{References}

1. Hay RJ, Johns NE, Williams HC, Bolliger IW, Dellavalle RP, Margolis DJ, et al. The global burden of skin disease in 2010: an analysis of the prevalence and impact of skin conditions. Journal of Investigative Dermatology. 2014;134(6):1527-34.

2. Nicoli S, Bunge AL, Delgado-Charro MB, Guy RH. Dermatopharmacokinetics: factors influencing drug clearance from the stratum corneum. Pharm Res. 2009;26(4):865-71.

3. McCarley KD, Bunge AL. Pharmacokinetic models of dermal absorption. J Pharm Sci. 2001;90(11):1699-719.

4. Mitragotri S, Anissimov YG, Bunge AL, Frasch HF, Guy RH, Hadgraft $\mathbf{J}$, et al. Mathematical models of skin permeability: an overview. Int J Pharm. 2011;418(1):115-29.

5. Bouzom F, Ball K, Perdaems N, Walther B. Physiologically based pharmacokinetic (PBPK) modelling tools: how to fit with our needs? Biopharm Drug Dispos. 2012;33(2):55-71.

6. Hartmanshenn C, Scherholz M, Androulakis IP. Physiologically-based pharmacokinetic models: approaches for enabling personalized medicine. J Pharmacokinet Pharmacodyn. 2016;43(5):481-504.

7. Jamei M. Recent advances in development and application of physiologically-based pharmacokinetic (PBPK) models: a transition from academic curiosity to regulatory acceptance. Current Pharmacology Reports. 2016;2(3):161-9.

8. Yun Y, Edginton A. Correlation-based prediction of tissue-toplasma partition coefficients using readily available input parameters. Xenobiotica. 2013;43(10):839-52. 
9. Ye M, Nagar S, Korzekwa K. A physiologically based pharmacokinetic model to predict the pharmacokinetics of highly proteinbound drugs and the impact of errors in plasma protein binding. Biopharm Drug Dispos. 2016;37(3):123-41.

10. Yáñez JA, Remsberg CM, Sayre CL, Forrest ML, Davies NM. Flip-flop pharmacokinetics-delivering a reversal of disposition: challenges and opportunities during drug development. Therapeutic delivery. 2011;2(5):643-72.

11. Buxton I, Benet L. Pharmacokinetics: The dynamics of drug absorption, distribution, metabolism, and elimination. In: Bruton LL, Chabner BA, Knollmann BC, editors. Goodman and Gilman's The Pharmacological Basis of Therapeutics. 12th ed. New York: McGraw-Hill; 2011.

12. Brown RP, Delp MD, Lindstedt SL, Rhomberg LR, Beliles RP. Physiological parameter values for physiologically based pharmacokinetic models. Toxicol Ind Health. 1997;13(4):407-84.

13. Abd E, Yousef SA, Pastore MN, Telaprolu K, Mohammed $\mathrm{YH}$, Namjoshi S, et al. Skin models for the testing of transdermal drugs. Clinical pharmacology: advances and applications. 2016;8:163.

14. Godin B, Touitou E. Transdermal skin delivery: predictions for humans from in vivo, ex vivo and animal models. Adv Drug Deliv Rev. 2007;59(11):1152-61.

15. Morimoto Y, Hatanaka T, Sugibayashi K, Omiya H. Prediction of skin permeability of drugs: comparison of human and hairless rat skin. J Pharm Pharmacol. 1992;44(8):634-9.

16. Sato K, Sugibayashi K, Morimoto Y. Species differences in percutaneous absorption of nicorandil. J Pharm Sci. 1991;80(2):104-7.

17. Vecchia BE, Bunge AL. Animal models: a comparison of permeability coefficients for excised skin. Dermal absorption models in toxicology and pharmacology. 2005;24:305.

18. Montgomery DC, Peck EA, Vining GG. Introduction to linear regression analysis. John Wiley \& Sons; 2012.

19. Baumann K. Cross-validation as the objective function for variable-selection techniques. TrAC, Trends Anal Chem. 2003;22(6):395-406.

20. Leal LB, Cordery SF, Delgado-Charro MB, Bunge AL, Guy RH. Bioequivalence methodologies for topical drug products: in vitro and ex vivo studies with a corticosteroid and an anti-fungal drug. Pharm Res. 2017;34(4):730-7.

21. Braun M, Cawello W, Boekens H, Horstmann R. Influence of domperidone on pharmacokinetics, safety and tolerability of the dopamine agonist rotigotine. Br J Clin Pharmacol. 2009;67(2):209-15.

22. Yap C, Li H, Ji Z, Chen Y. Regression methods for developing QSAR and QSPR models to predict compounds of specific pharmacodynamic, pharmacokinetic and toxicological properties. Mini Rev Med Chem. 2007;7(11):1097-107.

23. Potts RO, Guy RH. Predicting skin permeability. Pharm Res. 1992;9(5):663-9.

24. Lien EJ, Gaot H. QSAR analysis of skin permeability of various drugs in man as compared to in vivo and in vitro studies in rodents. Pharm Res. 1995;12(4):583-7.

25. Kokate A, Li X, Williams PJ, Singh P, Jasti BR. In silico prediction of drug permeability across buccal mucosa. Pharm Res. 2009;26(5):1130-9.
26. Bujak R, Struck-Lewicka W, Kaliszan M, Kaliszan R, Markuszewski MJ. Blood-brain barrier permeability mechanisms in view of quantitative structure-activity relationships (QSAR). J Pharm Biomed Anal. 2015;108:29-37.

27. Ertl P. Polar surface area. Weinheim, Germany: Wiley-VCH Verlag GmbH \& Co. KGaA; 2008.

28. Ali J, Camilleri P, Brown MB, Hutt AJ, Kirton SB. Revisiting the general solubility equation: in silico prediction of aqueous solubility incorporating the effect of topographical polar surface area. J Chem Inf Model. 2012;52(2):420-8.

29. Clark DE. Rapid calculation of polar molecular surface area and its application to the prediction of transport phenomena. 2. Prediction of blood-brain barrier penetration. Journal of Pharmaceutical Sciences. 1999;88(8):815-21.

30. Kelder J, Grootenhuis PD, Bayada DM, Delbressine LP, Ploemen J-P. Polar molecular surface as a dominating determinant for oral absorption and brain penetration of drugs. Pharm Res. 1999;16(10):1514-9.

31. Palm K, Stenberg P, Luthman K, Artursson P. Polar molecular surface properties predict the intestinal absorption of drugs in humans. Pharm Res. 1997;14(5):568-71.

32. Winiwarter S, Bonham NM, Ax F, Hallberg A, Lennernäs $H$, Karlén A. Correlation of human jejunal permeability (in vivo) of drugs with experimentally and theoretically derived parameters. A multivariate data analysis approach. Journal of Medicinal Chemistry. 1998;41(25):4939-49.

33. Stenberg P, Luthman K, Ellens H, Lee CP, Smith PL, Lago A, et al. Prediction of the intestinal absorption of endothelin receptor antagonists using three theoretical methods of increasing complexity. Pharm Res. 1999;16(10):1520-6.

34. Potts RO, Guy RH. A predictive algorithm for skin permeability: the effects of molecular size and hydrogen bond activity. Pharm Res. 1995;12(11):1628-33.

35. El Maghraby G, Williams A, Barry B. Drug interaction and location in liposomes: correlation with polar surface areas. Int $\mathrm{J}$ Pharm. 2005;292(1-2):179-85.

36. Kwon JH, Liljestrand HM, Katz LE. Partitioning of moderately hydrophobic endocrine disruptors between water and synthetic membrane vesicles. Environmental Toxicology and Chemistry: An International Journal. 2006;25(8):1984-92.

37. Giachetti C, Assandri A, Mautone G, Tajana E, Palumbo B, Palumbo R. Pharmacokinetics and metabolism of N-(2-hydroxyethyl)-2, 5-[14 C]-pyrrolidine (HEP, epolamine) in male healthy volunteers. Eur J Drug Metab Pharmacokinet. 1996;21(3):261-8.

Publisher's Note Springer Nature remains neutral with regard to jurisdictional claims in published maps and institutional affiliations. 